\title{
ARRANJO DE PLANTAS EM MILHO: ANÁLISE DO ESTADO-DA-ARTE
}

\author{
MAIZE PLANT ARRANGEMENT: ANALYSIS OF THE STATE OF THE ART
}

\author{
Gilber Argenta ${ }^{1}$ Paulo Regis Ferreira da Silva ${ }^{2}$ Luís Sangoi $^{3}$
}

\section{- REVISÃO BIBLIOGRÁFICA -}

\section{RESUMO}

A interceptação da radiação fotossinteticamente ativa pelas plantas exerce grande influência sobre a sua performance quando outros fatores ambientais são favoráveis. A eficiência de utilização da radiação solar a campo é muito baixa. A escolha adequada do arranjo de plantas pode aumentar a interceptação da radiação, a eficiência de seu uso e o rendimento de grãos das culturas, por influenciar o índice de área foliar ângulo da folha e a distribuição de folhas no dossel. Esta revisão tem por objetivos analisar os principais fatores que afetam a escolha do arranjo de plantas em milho, a evolução da sua recomendação e as modificações introduzidas nas características de planta que a determinaram. A escolha do arranjo de plantas é influenciada pela cultivar, forma de uso do milho pelo produtor, nível tecnológico, época de semeadura e comprimento da estação de crescimento. As principais alterações no arranjo de plantas ocorreram após a introdução dos híbridos simples, que foi acompanhada pelo aumento do uso de fertilizantes e controle mais eficiente de plantas daninhas e de pragas. $O$ aprimoramento do manejo da cultura, associado ao uso de híbridos de alto potencial produtivo, contribuiu para o aumento da densidade de plantas e a redução do espaçamento entre linhas. Tais mudanças também foram viabilizadas por algumas modificações verificadas nas plantas, como os decréscimos no tamanho de pendão, número de plantas estéreis sob altas densidades, taxa de senescência foliar durante o enchimento de grãos, maior sincronia entre pendoamento e espigamento sob condições de estresse, menor estatura, número de folhas e acamamento de colmos e raízes $e$ redução no ângulo de inserção das folhas no colmo. Estas modificações aumentaram a tolerância da cultura ao estresse devido ao uso de altas densidades e possibilitaram alterações no arranjo de plantas. $O$ aumento no potencial de grãos de milho será possível através de incrementos na tolerância ao estresse e na uniformidade de emergência das plantas.

Palavras-chave: Zea mays L., densidade de plantas, espaçamento entre linhas, distribuição de plantas na linha, variabilidade entre plantas.

\section{SUMMARY}

The interception of photosynthetically active solar radiation has a great effect on plant's performance, particularly in favorable environments. Solar radiation use efficiency is very low under field conditions. The adequate choice of plant arrangement may enhance radiation interception, increasing grain yield, because it influences leaf area index, leaf angle and light distribution within the canopy. This review aims to analyze the main factors that affect plant arrangement definition in maize, the changes in plant arrangement recommendation and, the modification in plant traits that favored such changes. The choice of plant arrangement in the field must take into account cultivar, grower objective, input availability, planting date and length of the growing season. The major alterations in plant arrangement occurred after the commercial release of maize single-cross hybrids which was followed by an increase in fertilizer use and a more efficient weed control and insects. The association between better crop management and highly productive hybrids favored the increase in plant density and reduction in row spacing. Such cultural practice changes were also boosted by important plant modifications, including reduction in tassel size, decrease in the number of barren plants under high densities, smaller rate of leaf senescence during grain filling, better synchrony between

\footnotetext{
${ }^{1}$ Engenheiro Agrônomo, Mestre, Estudante de Doutorado do Programa de Pós-graduação em Fitotecnia, Faculdade de Agronomia da Universidade Federal do Rio Grande do Sul (UFRGS). Bolsista do CNPq. Av. Bento Gonçalves, 7712. CP 776. 91540-000, Porto Alegre/RS. E-mail: plantas@vortex.ufrgs.br. Autor para correspondência.

${ }^{2}$ Engenheiro Agrônomo, PhD., Professor Adjunto do Departamento de Plantas de Lavoura da Faculdade de Agronomia da UFRGS. Pesquisador do CNPq. E-mail: paulo.silva@vortex.ufrgs.br.

${ }^{3}$ Engenheiro Agrônommo, PhD., Professor da Universidade do Estado de Santa Catarina, CP 281. 88520-000, Lages/SC. E-mail: a21s@cav.udesc.br.
} 
anthesis and silking in stressful environments, smaller plant height and leaf number, lower rates of stem and root lodging and reduction in leaf angle insertion on the stem. These morphological and physiological changes increased maize endurance to high plant populations making possible to change plant display. Increase of maize yield potential will be possible through the increases in the stress tolerance and in the uniformity of plant emergence.

Key words: Zea mays, L., plant density, row spacing, intra-row plant distribution, plant-to-plant variability.

\section{INTRODUÇÃO}

Nos ecossistemas natural e cultivado, a atividade fotossintética das plantas resulta na conversão da energia solar em energia química, a qual é essencial para a produção vegetal. Assim, pode-se afirmar que a produção da planta é dependente da fotossíntese. Nestes ecossistemas, os elementos-chave são (i) interceptação da radiação fotossinteticamente ativa (400-700nm), (ii) utilização da energia gerada na redução de $\mathrm{CO}_{2}$ e de outros substratos (fotossíntese), (iii) incorporação de assimilados em novas estruturas na planta (biosíntese e crescimento) e (iv) manutenção da planta como uma unidade viva (LOOMIS \& AMTHOR, 1999).

A interceptação da radiação fotossinteticamente ativa pelo dossel exerce grande influência sobre o rendimento de grãos da cultura do milho quando outros fatores ambientais são favoráveis (OTTMAN \& WELCH, 1989). Uma das formas de se aumentar a interceptação de radiação e, conseqüentemente, o rendimento de grãos é através da escolha adequada do arranjo de plantas. A associação entre evolução do arranjo de plantas e aumento da produtividade de grãos de milho tem sido freqüentemente reportada na literatura (CARDWELL, 1982; RUSSEL, 1991; SANGOI, 2000). O arranjo de plantas pode ser manipulado através de alterações na densidade de plantas, no espaçamento entre linhas, na distribuição de plantas na linha e na variabilidade entre plantas (emergência desuniforme).

As alterações no arranjo de plantas em milho deveram-se às modificações de ordem genética, fisiológica, bioquímica e anatômica. Estas modificações foram incorporadas pelos programas de melhoramento nas últimas décadas, aumentando a tolerância da cultura ao estresse (TOLLENAAR et al., 1997; TOLLENAAR \& WU, 1999; SANGOI, 2000). Os objetivos desta revisão foram analisar a evolução da recomendação de arranjo de plantas em milho, as modificações introduzidas nas características de planta que a determinaram e os principais fatores que afetam a escolha do arranjo de plantas.

\section{ARRANJO DE PLANTAS COMO PRÁTICA DE MANEJO PARA POTENCIALIZAR O RENDIMENTO DE GRÃOS}

Para obtenção de altos rendimentos de grãos, deve-se maximizar a duração da interceptação da radiação, utilizar eficientemente a energia interceptada (fotossíntese), distribuir os novos assimilados na proporção ótima para formação de folhas, colmos, raízes e de estruturas reprodutivas e manter estes processos com custo mínimo para a planta (LOOMIS \& AMTHOR, 1999). Tais processos são bastante complexos, tornando muito difícil a maximização simultânea do uso destes fatores.

A influência dos fatores limitantes da produtividade de uma cultura pode ser melhor compreendida se o potencial máximo de seu rendimento for conhecido. No entanto, o ambiente impõe uma série de limitações para que o genótipo expresse o seu potencial, fazendo com que o rendimento obtido freqüentemente seja menor que o potencial esperado. $\mathrm{O}$ potencial de rendimento de uma cultura pode ser definido como o rendimento obtido quando cultivada em ambiente ao qual está adaptada, com nutrientes e água não limitantes, e com insetos, doenças, plantas daninhas, excessos hídricos e outros estresses efetivamente controlados (EVANS, 1993). A estimativa e a exploração dos limites de produtividade das culturas são pontos importantes que devem ser observados nos programas de melhoramento.

Além de fatores genéticos, a produtividade de uma cultura depende das condições de solo e de clima, particularmente da radiação solar (MELGES et al., 1989). A utilização de luz é o processo mais importante para a produtividade, porque é através da fotossíntese que a planta acumula matéria orgânica em seus tecidos. A quantidade de energia convertida e, portanto, a quantidade de massa seca produzida, depende da percentagem de absorção e da eficiência de utilização da energia absorvida. A faixa de comprimento de onda entre 400 e 700 nanômetros da radiação solar constitui a energia radiante fotossinteticamente ativa (LOOMIS \& WILLIAMS, 1963). Ela representa entre 46 e $50 \%$ da radiação solar global (BARNI et al., 1995).

A quantidade de radiação solar absorvida é um importante fator determinante da produtividade final de uma cultura. Vários estudos têm reportado relação linear entre fitomassa produzida e a energia 
radiante absorvida ao longo do ciclo para um grande número de espécies (TOLLENAAR \& BRUULSEMA, 1988). Entretanto, deve-se considerar que a conversão da radiação absorvida em massa seca depende de mudanças na fotossíntese em função de radiação e temperatura e da fração do carbono fixado pela fotossíntese consumido na respiração (GALLAGHER \& BISCOE, 1978).

O aproveitamento por uma cultura da luz na faixa do espectro visível depende do índice de área foliar e de parâmetros físicos, biológicos e alométricos que determinam a absorção da radiação incidente (BARNI, 1994). A máxima eficiência teórica da fotossíntese é de cerca de 11\% (GOOD \& EVANS, 1980). Entretanto, a eficiência real da fotossíntese das culturas a campo está longe deste valor. Em condições não limitantes, a eficiência fotossintética pode variar de 2,0 a 5,3\% (LOOMIS \& WILLIAMS ,1963).

A eficiência de utilização da radiação solar pelas culturas é baixa. Em milho, o arranjo de plantas constitui-se em prática de manejo importante para potencializar o rendimento de grãos. A figura 1 ilustra este aspecto, mostrando interação entre diferentes fatores que afetam a produtividade final de uma cultura. Pode-se observar que o rendimento de grãos é dependente da fotossíntese e da

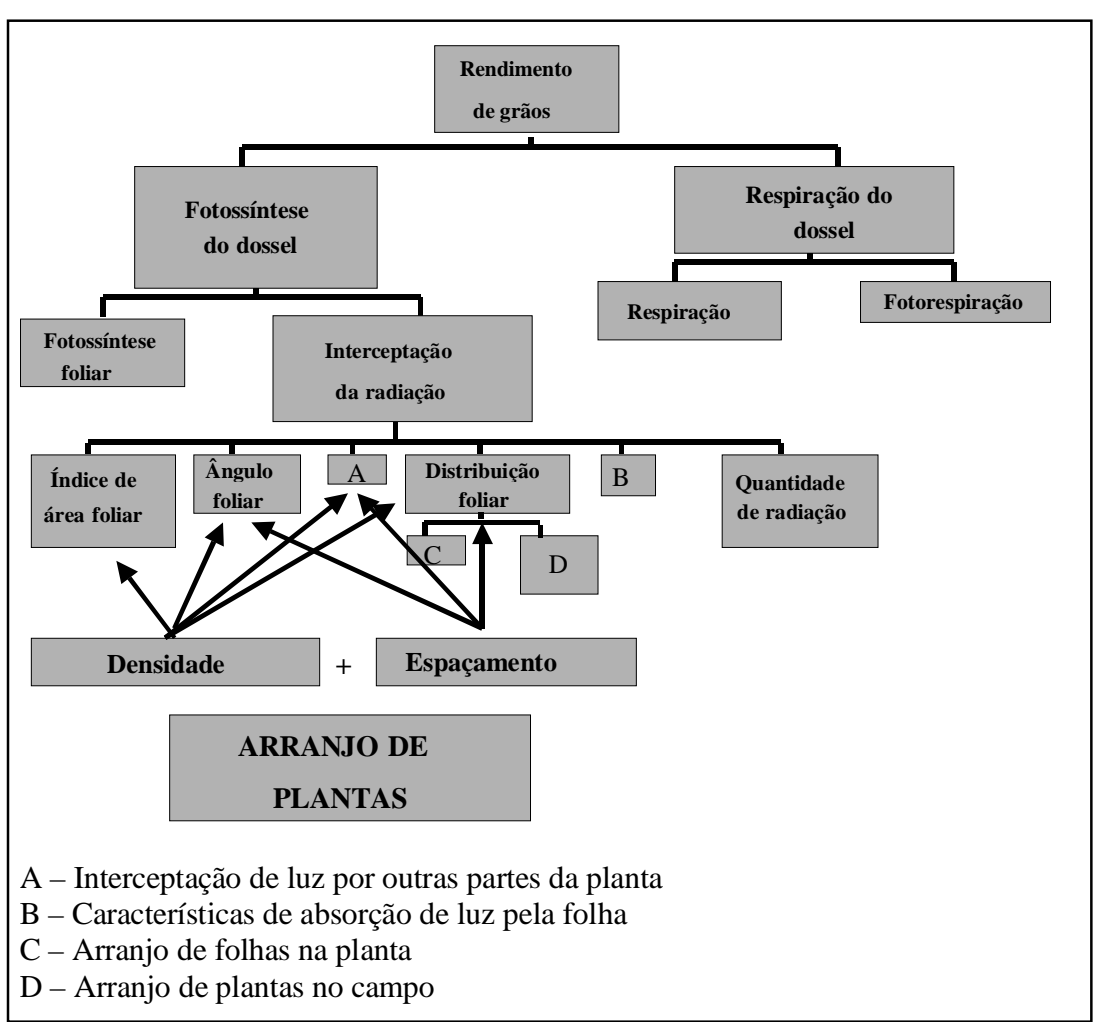

Figura 1 - Fluxograma dos fatores que afetam o rendimento de grãos das culturas. Fonte: Adaptado de GARDNER et al., 1985. respiração do dossel. Por sua vez, a fotossíntese do dossel é função da fotossíntese da folha e da interceptação da radiação solar. Já a interceptação da radiação solar é influenciada pelo índice de área foliar, ângulo da folha, interceptação de luz por outras partes da planta, distribuição de folhas (arranjo de folhas na planta e de plantas no campo), características de absorção de luz pela folha e pela quantidade de radiação incidente. Destes fatores, apenas a quantidade de radiação solar não é afetada pela escolha do arranjo de plantas.

Portanto, a escolha do arranjo de plantas adequado é uma das práticas de manejo mais importante para otimizar o rendimento de grãos de milho, pois afeta diretamente a interceptação de radiação solar, que é um dos principais fatores determinantes da produtividade (LOOMIS \& WILLIAMS, 1963; OTTMAN \& WELCH, 1989; SINCLAIR, 1993; EVANS, 1993; LOOMIS \& AMTHOR, 1999).

\section{FATORES QUE INFLUENCIAM A ESCOLHA DO ARRANJO DE PLANTAS}

Teoricamente, o melhor arranjo é aquele que proporciona distribuição mais uniforme de plantas por área, possibilitando melhor utilização de luz, água e nutrientes. As plantas podem ser distribuídas de várias formas, sendo que as variações na distância entre elas na linha e nas entre linhas determinam os diferentes arranjos na lavoura.

Os principais fatores que influenciam a escolha do arranjo de plantas de milho são: cultivar, objetivo do produtor, nível tecnológico, época de semeadura e duração da estação de crescimento na região de cultivo. Híbridos mais precoces (ciclo mais curto) requerem maior densidade de plantas em relação aos de ciclo normal para atingir seu potencial de rendimento (MUNDSTOCK, 1977a; SILVA, 1992; TOLLENAAR, 1992). Isso se deve ao fato de os híbridos mais precoces (superprecoces) geralmente apresentarem menor estatura, folhas menores, menor área foliar por planta e menor sombreamento do dossel da cultura (MUNDSTOCK, 1977a; 
SANGOI, 2000). Estas características morfológicas possibilitam a adoção de menor espaçamento entre plantas na linha e, conseqüentemente, de maior densidade de plantas. Esses híbridos normalmente requerem maior densidade de plantas para a maximização do rendimento de grãos, por necessitarem de mais indivíduos por área para gerar índice de área foliar capaz de potencializar a interceptação da radiação solar (SANGOI, 2000). As diferenças na resposta à densidade entre cultivares precoces e tardias são mais acentuadas quando o nível de produtividade é elevado. Com tetos de produtividade baixos, há pouco efeito do ciclo do genótipo na definição da densidade de plantas ótima. Com relação à redução no espaçamento entre linhas, os maiores benefícios em termos de rendimento de grãos são obtidos quando o teto de produtividade é superior a $6 \mathrm{t} / \mathrm{ha}$ e a densidade utilizada é maior que 4 plantas $/ \mathrm{m}^{2}$ (MUNDSTOCK, 1977b). O incremento no rendimento de grãos resultante da utilização de menores espaçamentos é devido à melhor distribuição de plantas na lavoura, que evita a excessiva concorrência por luz dentro da fila, a qual ocorre somente quando a densidade de plantas é alta. Além disso a redução no espaçamento entre linhas é mais efetiva, quando utilizados híbridos de menor porte, pois esses demoram para fechar o espaço entre linhas e, muitas vezes, nem conseguem sombrear toda a área (MUNDSTOCK, 1977b, ARGENTA et al., 2000).

Outro fator que afeta a escolha do arranjo de plantas é a forma de uso de milho na propriedade. Para produção de grãos, o arranjo de plantas recomendado depende do tipo de cultivar e das condições de manejo (PROGRAMA..., 1999). Para obtenção de altos rendimentos de grãos, a densidade geralmente utilizada varia de 5 a 7 plantas $/ \mathrm{m}^{2}$, com espaçamento entre linhas de 0,7 a $1,0 \mathrm{~m}$. Para produção de silagem, tanto de planta inteira como de grãos úmidos, o arranjo de plantas é o mesmo utilizado para produção de grãos. Para milho pipoca, a densidade recomendada é de 6,5 a 8,0 plantas $/ \mathrm{m}^{2}$, com espaçamento entre linhas de 0,75 a 0,90 . O emprego de maior densidade de plantas na produção de milho pipoca deve-se ao tipo de planta com menor estatura e poucas folhas e à necessidade de obtenção de grãos de maior qualidade, para melhorar o índice de expansão (PROGRAMA..., 1999). Para produção de milho doce e milho verde, recomendase densidade de plantas entre 3,5 a 4,0 plantas $/ \mathrm{m}^{2}$ (PROGRAMA..., 1999), pois é importante que as espigas tenham tamanho grande, para aumentar o rendimento industrial e atender às exigências dos consumidores do produto in natura. Outra forma especial de consumo natural deste cereal é o minimilho, que consiste no processamento de espigas jovens (comprimento de 4 a $10 \mathrm{~cm} \mathrm{e}$ diâmetro de 1 a $1,5 \mathrm{~cm}$ ) pela indústria de conservas alimentícias. Nesse caso, a densidade de plantas recomendada varia de 14 a 18 plantas $/ \mathrm{m}^{2}$ (PEREIRA FILHO et al., 2000).

A disponibilidade de água é, provavelmente, o principal fator que afeta a escolha da densidade ótima de plantas (LOOMIS \& CONNORS, 1992). A época mais crítica da planta de milho à deficiência hídrica situa-se no período entre duas a três semanas do espigamento (WESTGATE, 1994). Quando há alta probabilidade de falta de umidade nesta fase, deve-se diminuir a densidade para que o solo possa suprir as plantas com suas reservas hídricas (MUNDSTOCK, 1977a). Alguns trabalhos mostram que densidades mais elevadas só devem ser recomendadas sob condições de alta precipitação pluvial ou sob irrigação e com alto nível de manejo (MUNDSTOCK \& SILVA, 1989; PEIXOTO, 1996), pois com maior densidade aumenta-se $o$ índice de área foliar e, conseqüentemente, o consumo de água (TETIOKAGHO \& GARDNER, 1988). Outra prática que poderá ser adotada, quando há alta probabilidade de deficiência hídrica, é a redução no espaçamento entrelinhas, mantendo-se constante a densidade de plantas. Esssa medida pode diminuir a competição entre plantas por água, devido a sua distribuição mais eqüidistante (JOHNSON et al., 1998).

A necessidade nutricional das plantas é outro aspecto a ser considerado na escolha do arranjo de plantas em milho, pois a cultura é muito exigente em fertilidade do solo. $\mathrm{O}$ milho responde progressivamente a altas adubações, desde que os demais fatores estejam em níveis ótimos, sendo que o nitrogênio e o nutriente ao qual o milho apresenta melhor resposta de aumento de rendimento de grãos. Trabalhos com genótipos, densidades de planta e níveis de nitrogênio evidenciam que à medida que se eleva a densidade de plantas, são necessárias maiores doses de nitrogênio. Por outro lado, com baixa disponibilidade deste nutriente, na qual se espera menor rendimento de grãos, a densidade ótima recomendada deve ser reduzida (MUNDSTOCK, 1977a; PEIXOTO, 1996).

A época de semeadura e o comprimento da estação de crescimento também influenciam a escolha do arranjo de plantas de milho. Nas semeaduras do cedo (final do inverno e início da primavera), particularmente em regiões temperadas e sub-tropicais, tais como, respectivamente, o norte dos Estados Unidos (ANDERSON, 1995) e o sul do Brasil (MEROTTO Jr. et al.; 1997; ALMEIDA $\boldsymbol{e t}$ al., 2000) usualmente são requeridas maiores 
densidades de plantas. Isto é atribuído à menor radiação solar disponível e ao menor crescimento da planta sob temperaturas baixas (SANGOI, 2000). Nesta situação, a adoção de menores espaçamentos entre linhas pode aumentar o rendimento de grãos, por permitir melhor distribuição espacial das plantas e, conseqüentemente, maior interceptação da radiação solar.

Para a distribuição de plantas na linha (desuniformidade de emergência), que é outra forma de se manipular o arranjo de plantas em milho, o principal fator de influência é o tipo de semeadura, se manual (saraquá) ou mecanizada. Por sua vez, a variabilidade entre plantas é influenciada pela época de semeadura, vigor de semente e pela precisão da semeadura. Semeaduras do cedo, aliada ao uso de sementes menos vigorosas e à variação na profundidade de semeadura aumentam a variabilidade entre plantas, por influenciarem a velocidade de emergência das plântulas, devido às menores temperaturas do solo.

\section{EVOLUÇÃO DA RECOMENDAÇÃO DE ARRANJO DE PLANTAS EM MILHO}

A recomendação de arranjo de plantas em milho foi alterada ao longo do tempo, junto com as modificações de ordem genética, fisiológica, bioquímica e anatômica introduzidas na planta e a evolução do manejo cultural. Incrementos lineares no rendimento de grãos ocorreram na região do milho, nos EUA, nos últimos 70 anos, devido ao início de comercialização de híbridos duplos na década de 30 e dos híbridos simples em meados da década de 60 (RUSSEL, 1991). No Brasil as grandes alterações no arranjo de plantas de milho ocorreram a partir da década de 40, devido à utilização de híbridos duplos (PATERNIANI, 1993). A utilização de híbridos permitiu maior uso de fertilizantes, controle mais eficiente de plantas daninhas, avanços no manejo da cultura e aumento da densidade de plantas (DUVICK \& CASSMAN, 1999). Segundo CARDWELL (1982), somente a elevação na densidade de plantas foi responsável pelo incremento de $21 \%$ no rendimento de grãos de milho no período de 1930-1979 na região de Minnesota (EUA).

A densidade de plantas é uma das práticas culturais que mais afeta o rendimento de grãos de milho, que é a espécie da família das Poaceas mais sensível a sua variação (ALMEIDA \& SANGOI, 1996). Isso porque os híbridos modernos não perfilham e, usualmente, produzem somente uma espiga por planta e portanto, não possuem a capacidade de compensar eventuais falhas na emergência como as demais espécies desta família. Sob altas densidades, aumenta a competição inter-planta por luz, água e nutrientes (SANGOI, 2000) o que afeta o rendimento final porque estimula a dominância apical, induz a esterilidade, decresce o número de espigas produzidas por planta e o número de grãos por espiga (SANGOI \& SALVADOR, 1998). Portanto, o rendimento de grãos de milho aumenta com o incremento na densidade de planta até atingir um nível ótimo, que é determinado pelo genótipo e pelas condições do ambiente e diminui com posteriores aumentos na densidade.

Ao avaliar o comportamento de genótipos de milho cultivados nos EUA em diferentes épocas do século XX (variedade de polinização aberta e híbridos das décadas de 30,40,50,60, 70 e 80), em três densidades de planta $\left(3,1,4,8\right.$ e 6,4 plantas $\left./ \mathrm{m}^{2}\right)$, RUSSEL (1984) constatou que o rendimento de grãos diminuiu à medida que se elevou a densidade de plantas para as variedades de polinização aberta e para os híbridos das décadas de 30, 40 e 50. No entanto, o rendimento de grãos dos híbridos das décadas de 60,70 e 80 aumentou com o incremento da densidade de plantas de 3,1 para 6,4 plantas $/ \mathrm{m}^{2}$. Esta alteração na resposta de híbridos à densidade de plantas a partir da década de 60, é atribuída a algumas modificações introduzidas na planta ao longo do tempo, as quais serão discutidas posteriormente.

Até a introdução dos híbridos simples, a densidade de plantas recomendada nos EUA situavase ao redor de 3 plantas $/ \mathrm{m}^{2}$ (RUSSEL, 1991). A partir da década de 60, a densidade de plantas foi aumentando em função das modificações introduzidas na planta e do manejo da cultura, chegando à recomendação de 9 plantas $/ \mathrm{m}^{2}$, para condições de alto manejo (OLSON \& SANDERS, 1988). No estado do Rio Grande do Sul, a densidade de planta recomendada varia de 2 a 7 plantas $/ \mathrm{m}^{2}$, dependendo do tipo de cultivar e das condições de manejo (PROGRAMA..., 1999).

Em trabalhos desenvolvidos na região sul do Brasil para determinar a densidade ótima de plantas em híbridos de milho com elevado potencial de rendimento de grão (MUNDSTOCK, 1977a, SILVA et al., 1999 e ALMEIDA $\boldsymbol{e t}$ al., 2000), os máximos rendimento de grãos foram obtidos com densidades iguais ou superiores a 8 plantas $/ \mathrm{m}^{2}$, evidenciando que a recomendação de densidade de até 7 plantas $/ \mathrm{m}^{2}$ pode ser ampliada para 8 plantas $/ \mathrm{m}^{2}$, em ambientes favoráveis para obtenção de altos tetos de rendimento de grãos e com híbridos tolerantes a acamamento (ALMEIDA et al., 2000). 
Além de densidade, outra forma de se manipular o arranjo de plantas em milho é através do espaçamento entre linhas. $\mathrm{O}$ espaçamento entre linhas recomendado no RS varia de 0,7 a $1,0 \mathrm{~m}$ (PROGRAMA..., 1999). O espaçamento tradicional de um metro entre linhas é originário do uso de animais nas lavouras para realização de tratos culturais (MUNDSTOCK, 1977b). Com a introdução do uso de herbicidas no controle de plantas daninhas, a adoção do espaçamento amplo tem sido questionada. Menores espaçamentos entre linhas permitem melhor distribuição espacial das plantas, aumentando a sua eficiência na interceptação de luz (FLÉNET $\boldsymbol{e t}$ al., 1996). Muitas vezes, isto se reflete em incrementos do rendimento de grãos (KARLEN \& CAMP, 1985; PARVEZ $\boldsymbol{e t}$ al., 1989; MURPHY et al., 1996; ARGENTA et al., 2000), devido ao aumento da produção fotossintética líquida (BULLOCK $\boldsymbol{e t} \boldsymbol{a l} .$, 1988). O incremento do rendimento de grãos com redução do espaçamento entre linhas é atribuído à maior eficiência na interceptação de radiação e ao decréscimo de competição entre plantas na linha por luz, água e nutrientes, devido a sua distribuição mais eqüidistante das plantas (JOHNSON et al., 1998).

Os incrementos potenciais no rendimento de grãos de milho obtidos com o uso de espaçamentos menores $(0,5$ e $0,7 \mathrm{~m})$ do que os convencionalmente utilizados $(0,8-1,0 \mathrm{~m})$ variam de 5 a 10\% (MUNDSTOCK, 1977b). ARGENTA et al. (2000) verificaram que o efeito da redução do espaçamento entre linhas sobre o rendimento de grãos dependeu do híbrido utilizado e da densidade de plantas. Em um dos experimentos, o rendimento de grãos aumentou linearmente com redução do espaçamento de $1,0 \mathrm{~m}$ para $0,4 \mathrm{~m}$ para o híbrido Cargill 901 (incremento de $716 \mathrm{~kg} / \mathrm{ha}$ para cada $20 \mathrm{~cm}$ de redução no espaçamento), na densidade de 5 plantas $/ \mathrm{m}^{2}$. Para o outro híbrido (XL 212), não houve resposta à alteração no espaçamento entre linhas. No segundo experimento, os dois híbridos testados aumentaram linearmente o rendimento de grãos à medida que se reduziu o espaçamento de $1,0 \mathrm{~m}$ para $0,4 \mathrm{~m}$ (incrementos de 280 e de $130 \mathrm{~kg} / \mathrm{ha}$ para cada $20 \mathrm{~cm}$ de redução no espaçamento, respectivamente, para C 901 e XL 214), na densidade de 5 plantas $/ \mathrm{m}^{2}$. No entanto, na maior densidade $\left(6,5\right.$ plantas $\left./ \mathrm{m}^{2}\right)$, em que teoricamente a redução do espaçamento seria mais benéfica, não houve efeito de espaçamento sobre o rendimento de grãos, para os dois híbridos. Os autores atribuíram esta resposta diferencial ao fato de que em densidades maiores que 5 plantas $/ \mathrm{m}^{2}$, a vantagem da melhor distribuição espacial no menor espaçamento entre linhas pode ser suprimida em função da maior competição intraespecífica devida ao maior número de plantas.

Mesmo que, em algumas situações, a redução do espaçamento entre linhas não resulte em aumento do rendimento de grãos do milho, a sua adoção pode ser justificada pelo aumento da competitividade com plantas daninhas, devido à maior quantidade de luz que é interceptada pelo dossel da cultura (TEASDALE, 1995), pela utilização mais eficiente de máquinas, principalmente de semeadoras, pois possibilita a semeadura do milho no mesmo espaçamento da soja e também maior velocidade de semeadura em relação ao espaçamento tradicional. Por outro lado, o uso de espaçamentos mais estreitos pode dificultar a realização de tratos culturais em pós-emergência. A colheita, que se constituía em outra limitação, está sendo minimizada devido ao surgimento de plataformas que possibilitam colheita com espaçamento menor entre linhas.

O arranjo de plantas de milho também pode ser manipulado pela distribuição das plantas na linha. No estado do Rio Grande do Sul, $70 \%$ do milho é produzido por produtores com área menor do que 3,3ha (PROGRAMA...,1999), em que a maior parte da semeadura é realizada manualmente (saraquá), colocando-se duas ou mais sementes por cova. Trabalhos experimentais, conduzidos durante dois anos no estado de Santa Catarina, evidenciaram que a distribuição uniforme de plantas na linha não resultou em maiores rendimentos de grãos, em comparação a arranjos com duas ou mais plantas por cova (SANGOI, 1990). Resultados similares foram obtidos por RIZZARDI et al. (1994) no estado do Rio Grande do Sul, ao avaliarem diferentes formas de distribuição de plantas na linha, em dois espaçamentos entre linhas. Nesse trabalho, os autores concluíram que o milho foi capaz de compensar espaços deixados pela desuniformidade de emergência, desde que fosse mantida constante a densidade de plantas. No entanto, ROSSMANN \& COOK (1966) e SCHUBECK \& YOUNG (1970) nos EUA demonstraram que a distribuição de plantas de forma isolada e uniforme na linha pode incrementar o rendimento de grãos em até $13 \%$, sob condições de adequada fertilidade do solo e híbridos com alto potencial produtivo.

Outro fator que afeta o rendimento de grãos de milho, é a variabilidade verificada entre plantas numa mesma lavoura. GLENN \& DAYNARD (1974) demonstraram que a desuniformidade entre plantas diminui o rendimento de grãos e sugeriram que as práticas culturais que possibilitem estabelecimento uniforme da comunidade, como distribuição regular de sementes 
e profundidade de semeadura homogênea, poderiam maximizar o rendimento de grãos. FORD \& HICKS (1992) observaram reduções de $5 \%$ e 12,8\% no rendimento de grãos de milho quando se atrasou, respectivamente, em 7 e 14 dias a implantação de metade da densidade de plantas. MEROTTO Jr. et al. (1999) concluíram que a variabilidade na emergência de plantas diminuiu o rendimento de grãos e limitou a resposta do milho ao incremento da densidade de plantas. A redução no rendimento foi associada ao fato de que as plantas com emergência atrasada apresentam desvantagem competitiva por água, luz e nutrientes em relação às que emergem primeiro (TOLLENAAR \& WU, 1999). Portanto, o desenvolvimento de genótipos de milho com maior vigor, principalmente nas semeaduras do cedo, torna-se ferramenta importante para minimizar a variabilidade entre plantas.

\section{ALTERAÇÕES NA PLANTA ASSOCIADAS À MODIFICAÇÕES NO ARRANJO DE PLANTAS}

O milho foi a cultura que apresentou os maiores incrementos de rendimento de grãos durante o período de 1940 a 1990 nos EUA (RUSSELL, 1991). Segundo TOLLENAAR \& WU (1999), a elevação do rendimento de grãos é atribuída a mudanças nas práticas culturais, ao melhoramento genético, às alterações climáticas e à interação entre estes três fatores. A utilização de híbridos de milho, com maior potencial produtivo, permitiu maior uso de fertilizantes, principalmente os nitrogenados, controle mais eficiente de plantas daninhas, elevação da densidade de plantas (RUSSEL, 1991) e redução do espaçamento entre linhas (SANGOI, 2000; ARGENTA, 2000). Em trabalhos que avaliaram diferenças de rendimento de grãos entre híbridos modernos e antigos de milho, foram constatados que os ganhos de produtividade estiveram associados ao aumento da densidade de plantas (CARDWELL, 1982), devido à maior tolerância ao estresse sob densidade mais altas de plantas (TOLLENAAR $\boldsymbol{e t}$ al., 1997; SANGOI, 2000).

Muitas das alterações verificadas nas plantas ao longo do tempo não resultaram de seleção direta feita pelos melhoristas, visto que a maioria dos programas de melhoramento tem o rendimento de grãos per se como o seu objetivo principal. Algumas das modificações verificadas na planta contribuíram para aumentar o potencial de rendimento de grãos (DUVICK \& CASSMAN, 1999). Entre essas, destacam-se os decréscimos no teor de proteína dos grãos, com concomitante aumento no teor de amido e as reduções no tamanho de pendão, no número de plantas estéreis sob altas densidades e na taxa de senescência da folha durante o enchimento de grãos (DUVICK \& CASSMAN, 1999). Outra alteração importante foi a redução do intervalo entre pendoamento e espigamento sob altas densidades de planta (PEIXOTO, 1996; SILVA $\boldsymbol{e t}$ $\boldsymbol{a l .}$, 1999), que é uma característica indicadora de maior tolerância à deficiência hídrica (BOLANOS \& EDMEADES, 1996).

As modificações verificadas na arquitetura de planta de milho, tais como menor estatura, menor número de folhas, folhas mais eretas (ALMEIDA $\boldsymbol{e t} \boldsymbol{a l} .$, 2000) e pequeno acamamento de colmos e raízes (DUVICK \& CASSMAN, 1999), permitiram maior infiltração de luz no dossel, mesmo com alto índice de área foliar, e a diminuição de competição intraespecífica por recursos naturais sob altas densidades de planta. Este novo ideotipo de milho possibilitou alterações no arranjo de plantas que levaram a maior eficiência de uso da radiação solar em ambientes para obtenção de altas produtividades.

As principais mudanças, que conferiram ao milho maior tolerância ao estresse induzido pelo uso de altas densidades de plantas e que permitiram as alterações no arranjo de plantas, trouxeram outras vantagens aos híbridos modernos, entre as quais podem ser citadas: menor decréscimo do índice de colheita e menor acamamento de colmo (TOLLENAAR, 1992); maior tolerância a deficiência hídrica e a baixo nível de nitrogênio no solo (TOLLENAAR, 1989); menor redução da fotossíntese após ocorrência de baixas temperaturas noturnas durante o período de enchimento de grãos (DWYER \& TOLLENAAR, 1989); maior eficiência de uso de nitrogênio e de acumulação de massa seca durante o desenvolvimento inicial (McCULLOUGH et al., 1994a e b); maior tolerância à interferência de plantas daninhas (TOLLENAAR et al., 1997); e melhor equilíbrio entre fonte e demanda, pelo maior suprimento de assimilados para as raízes dos híbridos modernos durante o período de enchimento de grãos (RAJCAN \& TOLLENAAR, 1999a e b).

\section{CONCLUSÕES}

A manipulação do arranjo de plantas em milho, através de alterações na densidade de plantas, de espaçamento entre linhas, de distribuição de plantas na linha e na variabilidade entre plantas, é uma das práticas de manejo mais importantes para maximizar a interceptação da radiação solar, otimizar o seu uso e potencializar o rendimento de grãos.

As principais alterações no arranjo de plantas de milho, nas últimas décadas, foram o 
aumento na densidade de plantas e a redução na distância entre as linhas de semeadura. Tais mudanças foram estimuladas pela introdução de híbridos simples de maior potencial produtivo, pelo maior uso de fertilizantes, controle mais eficiente de plantas daninhas e por avanços no manejo da cultura.

As alterações no arranjo de plantas deveram-se ao aumento da tolerância do milho a estresses. A melhor adaptação dos híbridos modernos ao adensamento pode ser atribuída à modificações genéticas, morfológicas e fisiológicas, tais como os decréscimos no tamanho de pendão, número de plantas estéreis, taxa de senescência foliar durante o enchimento de grãos, intervalo entre pendoamento e espigamento, estatura e número de folhas, acamamento de colmos e raízes e no ângulo de inserção de folhas com o colmo.

Para que todas estas mudanças sejam bem utilizadas na escolha do arranjo de plantas de milho que maximize os recursos ambientes, é fundamental que se considere o ciclo da cultivar, objetivo da lavoura, nível de fertilidade do solo, disponibilidade hídrica, época de semeadura e o comprimento da estação de crescimento. A combinação dessas variáveis com o arranjo adequado de plantas contribuirá substancialmente para a melhoria da produtividade da cultura no sul do Brasil.

$\mathrm{O}$ aumento no potencial de rendimento de grãos de milho será possível através de incrementos na tolerância ao estresse e na uniformidade de emergência das plantas. Isto ocorrerá com maior sucesso, quando houver união de esforços dos pesquisadores das diferentes áreas de conhecimento, como melhoristas, fisiologistas e geneticistas moleculares.

\section{REFERÊNCIAS BILIOGRÁFICAS}

ALMEIDA, M.L., de, SANGOI, L. Aumento da densidade de plantas de milho para regiões de curta estação estival de crescimento. Pesquisa Agropecuária Gaúcha, Porto Alegre, v.2, n.2, p.179-183, 1996

ALMEIDA, M.L., de, MEROTTO Jr., A., SANGOI, L., $\boldsymbol{e}$ t al. Incremento na densidade de plantas: uma alternativa para aumentar o rendimento de grãos de milho em regiões de curta estação estival de crescimento. Ciência Rural, Santa Maria, v. 30, n. 1, p. $23-29,2000$

ANDERSON, I.C. Crop management. Ames : Iowa State University, 1995. 52p. (Agronomy 516 Course Work, 1).

ARGENTA, G., SILVA, P.R.F. da, BORTOLINI, C.G., et al Resposta de híbridos simples de milho à redução do espaçamento entre linhas. Pesquisa Agropecuária Brasileira, Brasília, 2000, no prelo.

BARNI, N.A. Modelos de crescimento, desenvolvimento e rendimento do girassol em função da radiação solar, temperatura e disponibilidade hídrica. Porto Alegre, 1994. 249p. Tese (Doutorado em Agronomia) - Programa de Pósgraduação em Agronomia, Faculdade de Agronomia, Universidade Federal do Rio Grande do Sul, Porto Alegre, 1994.

BARNI, N.A., BERLATO, M.A., BERGAMASCHI, H., $\boldsymbol{e}$ t al. Rendimento máximo do girassol com base na radiação solar e temperatura: I. Absorção da radiação solar fotossinteticamente ativa. Pesquisa Agropecuária Gaúcha. Porto Alegre, v.1, n.2, p.185-199, 1995.

BOLANOS, J., EDMEADES, G.O. The importance of the anthesis-silking interval in breeding for dought tolerance in tropical maize. Field Crops Research, Amsterdam, v.48, p.65-80, 1996.

BULLOCK, D.G., NIELSEN, R.L., NYQUIST, W.E. A growth analysis comparison of corn grown in conventional and equidistant plant spacing. Crop Science, Madison, v.28, n.2, p.254-258, 1988 .

CARDWELL, V.B. Fifty years of Minnesota corn production: sources of yield increase. Agronomy Journal, Madison, v.74, p.984-990, 1982.

DUVICK, D.N., CASSMAN, K.G. Post-green revolution in yield potential of temperate maize in the north-central united states. Crop Science, Madison, v.39, p.1622-1630, 1999.

DWYER, L.M., TOLLENAAR, M. Genetic improvement in photosynthetic response of hybrid maize cultivars, 1959 to 1988. Canadian Journal of Plant Science, Quebec, v.69, p.81-91, 1989.

EVANS, L.T. Processes, genes, and yield potential. In: BUXTON, D.R., SHIBLES, R., FORSBERG, R.A., et al. (Ed.) International Crop Science I. Madison : Crop Science Society os America, 1993. 895p.

FLÉNET, F., KINIRY, J.R., BOARD, J.E., et al. Row spacing effects on light extinction coefficients of corn, sorghum, soybean, and sunflower. Agronomy Journal, Madison, v.88, n.2, p.185-190, 1996.

FORD, J.H., HICKS, D.R. Corn growth and yield in uneven emerging stands. Journal of Production Agriculture, Cambridge, v.5, p.185-188, 1992

GALLAGHER, J.N., BISCOE, P.V. Radiation absorption, growth and yield of cereals. Journal of Agricultural Science, Cambridge, v.91, n.1, p.47-60, 1978.

GARDNER, F.P., PEARCE, R.B., MITCHELL, R.L. Physiology of crop plants. Ames : Iowa State University, 1985. 327p.

GLEMM, F.B., DAYNARD, T.B. Effects of genotype planting pattern, and planting density on plant-to-plant variability and grain yield of corn. Canadian Journal Plant Science, Quebec, v.54, p.323-330, 1974

GOOD, R.M., EVANS, L.T. Photosynthesis, plant productivity and crop yield. In: CARSON, P.S. The biology of crop productivity. NewYork : Academic, 1980. p.3-51.

JOHNSON, G.A., HOVERSTAD, T.R., GREENWALD, R.E. Integrated weed management using narrow corn row spacing, herbicides, and cultivation. Agronomy Journal, Madison, v.90, n.1, p.40-46, 1998. 
KARLEN, D.L., CAMP, C.R. Row spacing, plant population, and water management effects on corn in the Atlantic coastal plain Agronomy Journal, Madison, v.77, n.3, p.393-398, 1985.

LOOMIS, R.S., WILLIAMS, W.A. Maximum crop productivity: an estimate. Crop Science, Madison, v.3, n.1, p.67-72, 1963.

LOOMIS, R.S., CONNORS, D.J. Crop ecology: productivity and management in agricultural systems. Cambridge Cambridge University, 1992. 550p.

LOOMIS, R.S., AMTHOR, J.S. Yield potential, plant assimilatory capacity, and metabolic efficiencies. Crop Science, Madison, v.39, p.1584-1596, 1999.

McCULLOUGH, D.E., GIRARDIN, P.H., MIHAJLOVIC, M., $\boldsymbol{e}$ al. Influence of $\mathrm{N}$ supply on development and dry matter accumulation of an old and new maize hybrid. Canadian Journal of Plant Science, Quebec, v.74, p.471-477, 1994a.

McCUllough, D.E., AGUilerA, A., TOllenAAR, M. N uptake, $\mathrm{N}$ partitioning, and photosynthetic $\mathrm{N}$-use efficiency of an old and new maize hybrid. Canadian Journal of Plant Science, Quebec, v.74, p.479-484, 1994b.

MELGES, E., LOPES, N.F., OLIVA, M.A. Crescimento, produção de matéria seca e produtividade da soja submetida a quatro níveis de radiação solar. Pesquisa Agropecuária Brasileira, Brasília, v.9, p.1073-1080, 1989.

MEROTTO Jr., A., ALMEIDA., M.L. de, FUCKS, O. Aumento do rendimento de grãos de milho através do aumento da população de plantas. Ciência Rural, Santa Maria, v.27, n.4 p.549-554, 1997.

MEROTTO Jr., A., SANGOI, L., ENDER, M., et al. A desuniformidade de emergência reduz o rendimento de grãos de milho. Ciência Rural, Santa Maria, v.29, n.4, p.595-601, 1999.

MUNDSTOCK, C.M. Densidade de semeadura no milho para o Rio Grande do Sul. Porto Alegre : UFRGS/ASCAR, 1977a. 35p

MUNDSTOCK, C.M. Milho: distribuição da distância entre linhas. Lavoura Arrozeira, Porto Alegre, n.299, p.28-29, 1977b.

MUNDSTOCK, C.M., SILVA, P.R.F. da. Manejo da cultura do milho. Porto Alegre : UFRGS, Faculdade de Agronomia, Departamento de Plantas de Lavoura, 1989. 76p. (Datilografado)

MURPHY, S.D., YAKUBU, Y., WEISE, S.F., et al. Effect of planting patterns on intrarow cultivation and competition between corn and late emerging weeds. Weed Science, Champaing, v.44, n.6, p.856-870, 1996

OLSON, R.A., SANDERS, D.H. Maize production. In: SPRAGUE, G.F. DUDLEY, J.W. Corn and corn improvement. Madison : American Society of Agronomy, 1988. Cap.11, p.639-686.

OTTMAN, M.J., WELCH, L.F. Planting patterns and radiation interception, plant nutrient concentration, and yield in corn Agronomy Journal, Madison, v.81, n.2, p.167-174, 1989

PARVEZ, A.Q., GARDNER, F.P., BOOTE, K.J. Determinate and indeterminate type soybean cultivar responses to pattern, density, and planting date. Crop Science, Madison, v.29, n. 1, p.150-157, 1989
PATERNIANI, E. Métodos tradicionais de melhoramento do milho. In: BÜLL, L.T., CANTARELLA, H. Cultura do milho: fatores que afetam a produtividade. Piracicaba : POTAFOS, 1993. p.23-44.

PEIXOTO, C.M. Resposta de genótipos de milho à densidade de plantas, em dois níveis de manejo. Porto Alegre, 1996 , 118p. Dissertação (Mestrado em Agronomia) - Programa de Pós-graduação em Agronomia, Faculdade de Agronomia, Universidade Federal do Rio Grande do Sul, 1996.

PEREIRA FILHO, I.A., GAMA, E.E.G., CRUZ, J.C. Minimilho: efeito de densidades de plantio e cultivares na produção e em algumas características da planta de milho. In: CONGRESSO NACIONAL DE MILHO E SORGO, 23, 2000, Uberlândia. Resumos... Sete Lagoas : ABMS; Embrapa Milho e Sorgo; UFU, 2000. (1 CD ROM).

PROGRAMA MULTIINSTITUCIONAL DE DIFUSÃO DE TECNOLOGIA EM MILHO DO RIO GRANDE DO SUL. Recomendações técnicas para a cultura do milho no estado do Rio Grande do Sul. Porto Alegre : FEPAGRO; EMATER/RS; FECOTRIGO/RS, 1994. 130p. (Boletim Técnico, 1)

PROGRAMA MULTIINSTITUCIONAL DE DIFUSÃO DE TECNOLOGIA EM MILHO DO RIO GRANDE DO SUL. Recomendações técnicas para a cultura do milho no estado do Rio Grande do Sul. Porto Alegre : FEPAGRO; EMATER/RS; FECOAGRO/RS, 1999. 146p. (Boletim Técnico, 6).

RAJCAN, I., TOLLENAAR, M. Source-sink ratio and leaf senescence in maize. I. Dry matter accumulation and partitioning during the grain-filling period. Field Crops Research, Amsterdam, v.60, p.245-253, 1999a.

RAJCAN, I., TOLLENAAR, M. Source-sink ratio and leaf senescence in maize. I. Metabolism of nitrogen and soluble carbohydrates during the grain-filling period. Field Crops Research, Amsterdam, v.60, p.255-265, 1999 b.

RIZZARDI, M.A., BOLLER, W., DALLOGLIO, R. Distribuição de plantas de milho, na linha de semeadura, e seus efeitos nos componentes de produção. Pesquisa Agropecuária Brasileira, Brasília, v.29, n.8, p.1231-1136, 1994.

ROSSMANN, E.C., COOK, R.L. Preparation and date, rate and pattern of planting. In: PIERRE, W.H., ALDRICH, S.A., MARTIN, W.P. (Eds.). Advances in corn production, principles and practices. Iowa : State University, 1966. p.53-101.

RUSSELL, W.A. Agronomic performance of maize cultivars representing different eras of maize breeding. Maydica, Bergamo, v.29, p.375-390, 1984.

RUSSEL, W.A. Genetic improvement of maize yields. Advances in Agronomy, Cambridge, v.46, n.1, p.245-298, 1991.

SANGOI, L. Arranjo de plantas e características agronômicas de genótipos de milho em dois níveis de fertilidade. Pesquisa Agropecuária Brasileira, Brasília, v.25, n.7, p.12-14, 1990.

SANGOI, L., SALVADOR, R.J. Influence of plant height and leaf number on maize production at high plant densities. Pesquisa Agropecuária Brasileira, Brasília, v.33, n.3, p.297-306, 1998. 
SANGOI, L. Understanding plant density effects on maize growth and development: an important issue to maximize grain yield. Ciência Rural, Santa Maria, 2000, prelo.

SCHUBECK, F.E., YOUNG, H.G. Equidistant corn planting. Crops Soils Magazine, v.22, n.6, p.12-14, 1970.

SILVA, P.R.F. da. Densidade e arranjo de plantas em milho. In CONGRESSO NACIONAL DE MILHO E SORGO, 19, 1992, Porto Alegre, RS. Conferências... Porto Alegre : Secretaria da Agricultura - CIENTEC-ABMS, 1992. p.291294.

SILVA, P.R.F. da. ARGENTA, G., REZERA, F., et al. Resposta de híbridos de milho à densidade de plantas, em três épocas de semeadura. Pesquisa Agropecuária Brasileira, Brasília, v.34, n.4, p.585-595, 1999

SINCLAIR, T.R. Crop yield potential and fairy tales. In: BUXTON, D.R., SHIBLES, R., FORSBERG, R.A., et al. (Ed.). International crop science I. Madison : Crop Science Society os America, 1993. 895p. p.707-711.

TEASDALE, J.R. Influence of narrow row/high population corn on weed control and light transmittance. Weed Technology, Lawrence, v.9, n.1, p.113-118, 1995

TETIO-KAGHO, F., GARDNER, F.P. Responses of maize to plant population density. II. Reproductive development, yield and yield adjustments. Agronomy Journal, Madison, v.80, n.5, p.935-940, 1988 .

TOOLENAAR, M., BRUULSEMA, T.W. Efficiency of maize dry matter production during periods of complete leaf area expansion. Agronomy Journal, Madison, v.80, p.580-585, 1988

TOLLENAAR, M. Genetic improvement in grain yield of commercial maize hybrids grown in Ontario from 1959 to 1988. Crop Science, Madison, v.29, p.1365-1371, 1989.

TOLLENAAR, M. Is low plant density a stress in maize? Maydica, Bergamo, v.37, n.2, p.305-311, 1992.

TOLLENAAR, M., AGUILERA, A., NISSANKA, S.P. Grain yield is reduced more by weed interference in an old than in a new maize hybrid. Agronomy Journal, Madison, v.89, n.2, p.239-246, 1997.

TOLLENAAR, M., WU, J. Yield improvement in temperate maize is attributable to greater stress tolerance. Crop Science, Madison, v.39, p.1597-1604, 1999.

WESTGATE, M.E. Seed formation in maize during drought. In: BOOTE, K.J., BENNETT, J.M., SINCLAIR, T.R.,. et al. Physiology and determination of crop yield. Madison: American Society of Agronomy, 1994. Cap.15, p.361-364.

Ciência Rural, v. 31, n. 6, 2001. 